\title{
De víctimas a sobrevivientes: la fuerza poiética y resiliente del cuidar
}

From victims to survivors: the poietic and resilient force of caring

\author{
Irene Comins-Mingol / cominsi@uji.es \\ Universitat Jaume I, Castellón, España
}

\begin{abstract}
This article presents, from a philosophical perspective, the potential of the praxis of care as an autopoietic and performative force, key for the reconstruction and redefinition of human being as an agent. Likewise, in relation to the above, the praxis of caring is a fundamental pillar of resilience, the human capacity to overcome adversity. Caregivers, through and as a result of the practice of caring, weave affective networks, take some control over their lives and regain a sense of dignity and self-worth. The text offers an overview of these and other contributions of the praxis of caring to resilience and the redefinition of the subject as an agent. The theoretical approach is accompanied with concrete examples from the experience of displaced women victims of the armed conflict in Colombia.
\end{abstract}

Key words: philosophy, care ethics, culture of peace, resilience, poiesis.

Resumen: En este artículo se presenta, desde una perspectiva filosófica, la praxis del cuidar como fuerza autopoiética, performativa, de reconstrucción y resignificación del ser humano como agente. Asimismo, y en relación con lo anterior, se propone la praxis del cuidar como pilar fundamental de resiliencia, de la capacidad humana para superar situaciones adversas y sobreponerse satisfactoriamente. Las personas cuidadoras, a través y como resultado de la praxis del cuidar, tejen redes afectivas, toman cierto grado de control sobre su vida y recobran el sentido de la dignidad y de la propia valía. El texto hace una revisión de éstas y otras contribuciones de la praxis del cuidar a la resiliencia y la resignificación del sujeto como agente. La aproximación teórica del artículo se complementa con ejemplos concretos tomados de la experiencia de mujeres desplazadas víctimas del conflicto armado en Colombia. Palabras clave: filosofía, ética del cuidado, cultura de paz, resiliencia, poiesis. 


\section{Introducción $^{1}$}

En este artículo se analiza, desde una perspectiva filosófica, el potencial de la praxis del cuidar como fuerza autopoiética, de resignificación y empoderamiento del ser humano como agente. Asimismo, y en relación con lo anterior, se presenta la praxis del cuidar como pilar fundamental de resiliencia, de la capacidad humana para superar situaciones adversas y sobreponerse satisfactoriamente. Para ello se han organizado los contenidos del artículo en cuatro apartados.

En el primero se aborda el marco teórico desde el cual se realiza el análisis; podemos situarlo en el cruce vectorial entre la filosofía, los estudios de género y la investigación para la paz. Una vez presentado el marco teórico, en el segundo apartado haremos una breve introducción y contextualización de la filosofía del cuidar, eje central del artículo que nos ocupa.

En el tercer apartado se abordan las contribuciones de la praxis del cuidar a la construcción del sujeto como agente, o lo que hemos denominado la dimensión autopoiética del cuidar. Finalmente, en el cuarto apartado, y enlazado con el punto anterior, se señalarán las contribuciones del cuidar como fuente de resiliencia. Y es que las personas cuidadoras, a través y como resultado de la praxis del cuidar, tejen redes afectivas, toman un grado de control sobre su vida y recobran el sentido de la dignidad y de la propia valía. En el texto se apuntarán éstas y otras contribuciones de la praxis del cuidar a la resiliencia.

A lo largo del artículo, especialmente en el último epígrafe, la aproximación teórica se complementará con ejemplos concretos tomados de la experiencia de mujeres desplazadas víctimas del conflicto armado en Colombia. En concreto, los testimonios recogidos por el proyecto de la Comisión de Verdad y Memoria de Mujeres Colombianas; una iniciativa de la Ruta Pacífica de Mujeres Colombianas para recuperar la memoria de las mujeres víctimas del conflicto armado colombiano. ${ }^{2}$ Dicho proyecto está editado en dos volúmenes bajo el título La Verdad de las Mujeres. Victimas del Conflicto Armado en Colombia, el cual documenta 932 historias de mujeres y 9 casos colectivos. ${ }^{3}$

1 Este estudio se inserta en el Proyecto de Investigación "De víctimas a indignados: visibilidad mediática, migración de imágenes, espectacularización de los conflictos y procesos de transformación social hacia una cultura de paz", con referencia P1.1A2012-05 y financiado por la Universitat Jaume I de Castellón.

2 Uno de los objetivos del proyecto es que sirva como punto de partida para una futura Comisión de la Verdad en Colombia.

3 Existen diferentes movimientos de mujeres por la paz en Colombia. Además de la Ruta 


\section{Filosofía, género e Investigación para la Paz}

La filosofía contemporánea sólo recientemente ha empezado a incorporar de manera seria la perspectiva de género en el análisis crítico sobre el ser humano y su mundo de experiencia. Como señala Celia Amorós (2006: 260), a lo largo de la historia las mujeres han sido objeto de un proceso, sordo pero sistemático, de invisibilización epistemológica. En los últimos años, y aunque todavía queda mucho camino por recorrer, la filosofía viene comprometiéndose cada vez más con proyectos epistemológicos no excluyentes, sensibles a la perspectiva de género.

Además, esa apertura epistemológica surge en muchas ocasiones fruto del compromiso creciente de la filosofía por la praxis cotidiana, tanto a escala local como global, de la convivencia humana, la transformación pacífica de conflictos y la construcción de la paz (Comins, 2010). Las reflexiones y aportaciones que se están realizando en este sentido se orientan en dos ámbitos principales de trabajo.

Por un lado, hay un esfuerzo por analizar críticamente, visibilizar y denunciar la propia exclusión epistemológica de las mujeres por parte del pensamiento occidental, y también, en un sentido más amplio, denunciar la violencia directa, estructural y cultural que vienen padeciendo (Galtung, 2003). Por otro lado, hay también una serie de investigaciones que ponen sus esfuerzos en rescatar, reconstruir y visibilizar el legado, las experiencias históricas y socialmente construidas de las mujeres, enriqueciendo -y a veces cuestionando- los paradigmas clásicos del pensamiento androcéntrico occidental, en materias tan dispares como ética, ecología, desarrollo, política o economía.

Ambas líneas de trabajo no son sólo fundamentales sino que se construyen en interacción. Y en las dos hay, además, un claro compromiso de la filosofía en estar vinculada con la práctica, con la realidad cotidiana y con las posibilidades de transformación continua de esa realidad. En ese sentido, la filosofía contemporánea, de mano de la teoría feminista, trata de incorporar las críticas recibidas por "haber mantenido su teorización apartada de la práctica y de la experiencia de la vida" (Reverter, 2010: 154).

La filosofía contemporánea no sólo se ha ayudado de la teoría feminista a la hora de realizar ese giro práctico, comprometido, para convertirse en una filosofía emancipadora. Cada vez son más las disciplinas que entran a dialo-

Pacífica de las Mujeres, podemos destacar, entre otros, el Movimiento de Mujeres contra la Guerra y la Asociación Nacional de Mujeres Campesinas, Negras e Indígenas de Colombia (ANMUCIC). 
gar y enriquecer la dimensión práctica, aplicada de la filosofía, tal es el caso de la Investigación para la Paz, Peace Research. Así, por ejemplo, en la Cátedra Unesco de Filosofía para la Paz de la Universitat Jaume I de Castellón, en España, venimos apostando por una filosofía comprometida, que bebe de la Investigación para la Paz para desarrollar una reflexión crítica a la altura de los tiempos.

La Investigación para la Paz nace en el norte de Europa a mediados de la década de 1930, y a pesar de su reciente historia experimenta una interesante evolución. La vieja agenda de la Investigación para la Paz tomó como objeto de estudio la guerra, llegando a obtener y generar una gran riqueza de información y matices sobre la misma. Sin embargo, se descuidaba el análisis de las condiciones, características y mapa de ruta de la construcción de la paz, que quedaba reducida a una definición mínima, como negativo de la guerra.

Hoy en día, la nueva agenda de la Investigación para la Paz es consciente de la necesidad de superar el "paradigma de la negatividad" (Martínez Guzmán, 2004: 480). Así, partiendo de un concepto de paz imperfecta, se considera un objetivo fundamental de la Investigación para la Paz reconstruir y poner en valor las diferentes experiencias de paz allí donde las haya, convencidos de que el abordaje y visibilización epistemológica de la paz contribuye a su multiplicación y expansión (Muñoz, 2001).

Y es que el reconocimiento de las paces allí donde se dan es fuente de compromiso normativo - no hay excusa, la paz es posible, por tanto hay responsabilidad-, pero también es la mejor cura frente al desánimo, el abandono y el conformismo; nos proporciona energía, ánimo, esperanza, coraje y, sobre todo, el aprendizaje y el ejemplo para construir la paz.

La filosofía para la paz se desarrolla en el marco de esta nueva agenda de la Investigación para la Paz, es una filosofía comprometida con la recuperación y la visibilización del potencial humano para la paz (Martínez, Comins y París, 2009: 108), que apuesta por la reconstrucción normativa de nuestras competencias para hacer las paces. En el marco de ese enfoque, hemos desarrollado, entre otras, una teoría del cuidar como competencia humana para la paz. Y a la hora de reconstruir el cuidado como práctica ha sido fundamental acercarnos al trabajo que se viene llevando a cabo en la Investigación para la Paz con perspectiva de género.

Los estudios de género se incorporan de forma generalizada a la Investigación para la Paz a partir de 1980 (Díez y Sánchez, 2010), y lo hacen desde dos líneas de trabajo diferentes, paralelas a las anteriormente mencionadas en la filosofía con perspectiva de género. 
Por un lado, una línea crítica, que nace de la necesidad de hacer un análisis-diagnóstico de la situación de la mujer y de la opresión a la cual se ha visto sometida a lo largo de la historia. Una línea de trabajo imprescindible de denuncia y crítica de la subordinación de la mujer y la negación de sus derechos.

Esta fundamental línea de trabajo ha sido también el motor que condujo al movimiento de la Ruta Pacífica de Mujeres en Colombia a elaborar lo que puede considerarse la primera Comisión de Verdad y Memoria de mujeres en el mundo. La visibilización y denuncia de la profundidad y extensión de la violencia que sufren las mujeres es uno de los aportes fundamentales de la obra La Verdad de las Mujeres. Víctimas del Conflicto Armado en Colombia.

Por otro lado, una línea constructiva, la cual arranca de la convicción de que la experiencia de las mujeres en la historia es un legado imprescindible que ha alimentado valores de paz y de sostenimiento de la vida. Esta experiencia debe ser visibilizada para que podamos reconstruir desde ella los valores propios de una Cultura de Paz (Breines et al., 2002).

Dicha línea constructiva tratará de tomar como objeto de estudio no la violencia sino la paz, el legado de saberes y experiencias de las mujeres en su contribución a la sostenibilidad de la vida y como constructoras de paz. La reconstrucción de ese legado nos va a comprometer necesariamente con el objetivo de resignificar las relaciones de género, tal y como las conocemos, y proponer un modelo de ser persona más pacífico, relacional, justo y felicitante.

Ambas líneas de trabajo, crítica y constructiva, deben abordarse de forma sinérgica y complementaria para evitar caer en una visión victimizadora y reduccionista de la experiencia de las mujeres, que puede ningunear la complejidad del mundo de la experiencia de las mujeres e invisibilizar, por ejemplo, el importante papel que han desarrollado y desarrollan como constructoras de paz.

La imagen de las mujeres como víctimas es paralizante y no hace justicia a la diversidad, riqueza y empuje de los grupos de mujeres que se oponen a la guerra y se apoyan en la solidaridad mutua para ofrecer visiones alternativas de la realidad [...]. Por eso dar voz a quienes sufren y tratar de atajar ese sufrimiento no ha de impedirnos el oír y decir la vitalidad y la fuerza con la que tratan de seguir con sus vidas (Magallón, 2006: 41).

Además, como señala Carmen Magallón (2006: 41), la mirada victimista no es sólo reduccionista sino también "reproductora de la mentalidad que subyace en el victimario".

La filosofía del cuidar se contextualiza dentro de la perspectiva constructiva, y analiza el legado de las mujeres en la construcción de la paz, no sólo 
como memoria histórica de reconocimiento de las aportaciones de las mujeres, sino sobre todo para reivindicar la incorporación de los valores de paz que habían sido asignados y desarrollados en exclusividad por ellas al conjunto de la humanidad, tornándolos en valores humanos y no de género.

\section{La filosofía del cuidar}

Una de las líneas importantes de trabajo de la filosofía feminista contemporánea se desarrolla en diálogo con las contribuciones de la ética del cuidar, tal y como fue definida por primera vez en 1982 por Carol Gilligan en la obra In a Different Voice. ${ }^{4}$ En esta obra, Gilligan explicitó la diferente capacidad moral que las mujeres desarrollan a la luz de la socialización y la práctica del cuidar. Hasta entonces la Teoría del desarrollo moral se ceñía sin excepciones a la teoría propuesta por Lawrence Kohlberg (1976), quien se basó en el estudio de 84 niños varones durante un periodo de más de veinte años. Gilligan (1986: 40) intentó completar la Teoría moral de Kohlberg incluyendo en su análisis las experiencias morales de las mujeres. Además, Gilligan detectó otra anomalía en la escala del desarrollo moral de Kohlberg y fue la puntuación persistentemente baja de las mujeres al ser comparadas con sus iguales varones (Benhabib, 1990: 20).

Ese desvío en la puntuación se debía a que la Teoría del desarrollo moral se había construido sólo de acuerdo con el estudio de la experiencia de hombres, pero se aplicaba pretendiendo universalidad tanto a las mujeres como a los hombres. Gilligan detectó en su análisis de las mujeres una diferente voz moral más relacional, que situaba como preferente la preservación de las relaciones, en oposición con la ética de la justicia, de la Teoría del desarrollo moral según Kohlberg, en la cual se sitúa como preferente la obediencia a normas morales universales.

Cabe señalar que esa diferente perspectiva moral de las mujeres es resultado de la división sexual del trabajo y de la aguda división entre lo público y lo privado. La socialización en y la praxis del cuidar implican el desarrollo de una serie de habilidades y valores morales como son: la empatía, la escucha, la paciencia o la ternura, entre otros, que también podrían desarrollar los hombres si compartieran el mismo mundo de experiencia. Hombres y mujeres desarrollan así, según Gilligan, dos perspectivas morales distintas en función de esa desigual atribución de responsabilidades: "Ética del Cuidado" y "Ética de la Justicia".

4 La primera traducción al castellano es de 1986, véase bibliografía (Gilligan, 1986). 
Victoria Camps ha resumido las características de la ética del cuidado en contraposición a la ética de la justicia de la siguiente manera (Pastor, 2007: 40): se trata de una ética relacional, donde lo que importa más que el deber es la relación con las personas; no se limita a concebir la ley, sino que le interesa su aplicación situacional; considera que la racionalidad debe mezclarse con la emotividad; se centra en la implicación y compromiso directo y casi personal con los otros, y añade un enfoque particularizado al enfoque abstracto y general de la ética de la justicia.

\section{La fuerza poiética del cuidar}

El término griego poiesis alude al acto de creación, Platón lo define como la causa que convierte cualquier cosa que consideremos de no-ser a ser. El ser humano tiene la capacidad de crear, pero también la capacidad de re-crearse, de reconstruirse a sí mismo, a veces de forma consciente, pero la mayoría de veces inconscientemente. Así, por ejemplo, nuestros hábitos, experiencias, costumbres tienen la capacidad de transformarnos como humanos, y es que, como afirma el refrán, lo que hacemos nos hace.

En el ámbito biológico, esa capacidad continua de producción y recreación del propio ser ha sido definida como autopoiesis, y es una característica definitoria de todo ser vivo, y por ende del ser humano (Maturana y Varela, 2006). En el ser humano, la autopoiesis toma, si cabe, una mayor significatividad, y contribuye a la comprensión performativa del ser humano que la filosofía contemporánea viene desarrollando. El obrar humano es esencialmente autopoiético, y es que a través de nuestras acciones no sólo transformamos el mundo exterior, sino también nos transformamos a nosotros mismos. De modo que el hacer humano es también un proceso permanente de rehacerse (Cruz, 2009: 141).

La praxis del cuidar tiene ese potencial poiético bidireccional, de doble vía, con capacidad de afectación sobre el entorno, pero también sobre uno mismo. La persona que cuida se transforma, resignifica, se rehace, a través del ejercicio del cuidar.

El pensamiento y la práctica del cuidar implican el desarrollo de valores morales, habilidades y competencias como son la empatía, la paciencia, la perseverancia, la responsabilidad, el compromiso, la escucha o la ternura. Valores todos ellos importantes en la construcción de una Cultura para la Paz, tal y como señala la investigadora para la paz Betty Reardon (2001: 85), quien afirma que una Cultura para la Paz es una Cultura del Cuidar. 
Además de estos valores morales, la práctica del cuidar contribuye a desarrollar tres grupos de habilidades fundamentales para la construcción de una Cultura para la Paz: para el desarrollo y sostenimiento de la vida; para la transformación pacífica de conflictos (Comins, 2009); para el compromiso cívico y social (Comins, 2013).

Estas habilidades no se circunscriben en exclusividad al espacio privado sino que se amplían hasta el ámbito público. Por ejemplo, Sara Ruddick (1989) en su obra Maternal Thinking: Towards a Politics of Peace señaló de qué modo la práctica del cuidado de los hijos desarrolla técnicas en las mujeres para la transformación pacífica de conflictos. Y es que más allá del cuidado de los hijos, la socialización en el valor del cuidado desarrolla de forma general técnicas pacíficas de transformación de los conflictos. Así, la praxis del cuidar es una fuente autopoiética y de paz fundamental, que debe ser por ello desgenerizada y compartida por todos los seres humanos por igual.

Además de la contribución del cuidar al desarrollo de habilidades y valores específicos de paz, es importante señalar las implicaciones más amplias de la praxis del cuidar como fuerza autopoiética, performativa, de reconstrucción y resignificación del ser humano como agente. En definitiva, la contribución de la praxis del cuidar a la construcción de sujetos que se reconocen con capacidad de afectación en el mundo, y por tanto con poder; constituyéndose el ejercicio del cuidar en una fuente de empoderamiento. Pero de un poder cuidadoso, resignificado, ni autoritario ni subordinante.

Siguiendo a Kenneth Boulding (1993) en su libro Las tres caras del poder, podríamos calificar este poder de integrativo en contraste con las otras "caras del poder", como puede ser la del poder destructivo. Un concepto de poder que podríamos vincular con el poder entendido como capacidad de concertación tal y como propone Hannah Arendt (2005). El concepto de ciudadania cuidadora ejemplifica esa dimensión transformadora del cuidar que es bidireccional, hacia el exterior y hacia el interior (Sevenhuijsen, 2003).

Las tareas del cuidar son necesarias en la vida cotidiana pero aún más en situaciones adversas, contribuyendo significativamente a la seguridad de los individuos y de los grupos. Como señala Reardon (2010: 227), "una alternativa al concepto dominante de seguridad manifiesto en la seguridad estatal militarizada es el concepto feminista de seguridad humana, que posee un carácter amplio, holístico y de género". En muchas ocasiones las mujeres en zonas de conflicto se convierten en las únicas proveedoras y protectoras de sus familias como esposas, madres y hermanas, porque sus esposos, hermanos, hijos y padres o han sido exiliados o los han matado o están en el frente (Raven-Roberts, 2002: 105). 
Cuando el ser humano contribuye con sus acciones a esa seguridad, no sólo está transformando su entorno sino resignificandose a sí mismo como agente, como sujeto activo, alejado de toda visión pasiva. Esa resignificación del sujeto como agente es un elemento clave en la capacidad de resiliencia que muchas mujeres manifiestan en situaciones adversas. En el siguiente apartado señalaremos algunos modos en que el cuidar puede convertirse en fuente, en anclaje, de resiliencia.

\section{La fuerza resiliente del cuidar}

El cuidado da respuesta a la inherente fragilidad y vulnerabilidad del ser humano y se constituye, aunque no siempre de forma suficientemente consciente, en elemento vertebrador de nuestro mundo de la vida. Sin embargo, a pesar de que las actividades del cuidar acompañan a los seres humanos a lo largo de la vida, y a pesar de su relevancia para el bienestar y el desarrollo humano, las implicaciones sociales, económicas y culturales del cuidar no han estado suficientemente abordadas.

Existe además, respecto a las tareas del cuidar, una desigual distribución de responsabilidades entre hombres y mujeres, siendo estas últimas las que histórica y tradicionalmente han venido desarrollando casi en exclusividad dichas actividades. Este hecho ha repercutido negativamente en las mujeres (con el fenómeno de la doble jornada laboral, el techo de cristal, el síndrome de la abuela esclava, etc.), pero también en los hombres (crisis ante el desempleo, la jubilación, falta de realización afectiva y emocional, etcétera).

La filosofía del cuidar, como venimos señalando, propone compartir las tareas del cuidar a lo largo de la trayectoria vital entre hombres y mujeres tanto por criterios de justicia, de equidad, como de felicidad y autorrealización. Además, si bien la importancia del cuidado en la vida cotidiana es fundamental, en situaciones adversas, límite, recobra como veremos una significatividad especial.

\section{Sobre el conflicto armado en Colombia}

En este artículo no se aborda el conflicto colombiano como tema central de análisis, sino a modo de ejemplo, con el propósito de ilustrar el potencial transformador del pensamiento y las prácticas del cuidar en situaciones extremas. Sin embargo, parece pertinente presentar una breve introducción, que no pretende ser exhaustiva ni completa, a la complejidad del conflicto colom- 
biano, que nos ayude a contextualizar los testimonios que se aportarán como ejemplo del cuidado como fuerza poiética y de resiliencia.

En los años sesenta estuvo activo en Colombia un movimiento guerrillero izquierdista alentado por la pobreza, la desigualdad y la naturaleza exclusiva de la élite política. La más conocida de las guerrillas fue y sigue siendo las FARC (Fuerzas Armadas Revolucionarias Colombianas). Desgraciadamente, "sus recursos económicos salen de la extorsión, el secuestro y (en aumento actualmente) los impuestos a la producción, procesamiento y venta de cocaína, y al hacer esto perdieron credibilidad política” (Cockburn, 2009: 43).

La incapacidad del Estado para destruir el movimiento guerrillero llevó a los ricos terratenientes, hombres de negocios y traficantes de droga a organizar y pagar sus propios ejércitos, los paramilitares. Con ello se establece el escenario de conflicto y violencia que azota Colombia, en sus diferentes actores armados: la guerrilla, el ejército y los paramilitares.

La violencia sexual contra las mujeres es endémica, y la cometen cualquiera de los grupos armados como castigo por asociarse al "bando equivocado", o como castigo a los enemigos (Cockburn, 2009: 44-45). "En muchas regiones y en forma creciente, la única salida que le queda a la gente es abandonar sus casas. Colombia ostenta la mayor crisis del mundo de desplazamientos internos, después de Sudán" (Cockburn, 2009: 45). Estos desplazados, provenientes de las zonas rurales se asientan principalmente en torno a las ciudades, y entre ellos hay una presencia mayoritaria de mujeres, muchas de ellas cabezas de familia.

Colombia se caracteriza también por la actividad y el compromiso de los movimientos sociales. Recientemente, las organizaciones femeninas con un análisis de género de la guerra están en alza. La más grande y conocida internacionalmente es la Ruta Pacífica de las Mujeres por la Negociación Política de los Conflictos, que reúne a más de 300 organizaciones y grupos de mujeres colombianas (Cockburn, 2009: 47).

Se trata de un movimiento pacifista comprometido, intransigente con el uso de las armas y que condena la violencia independientemente del grupo armado que la ejerza. Entre sus principales reivindicaciones, además del cese de la violencia, se encuentra el inicio de procesos de memoria, verdad, justicia y reparación.

Los testimonios de las mujeres víctimas del conflicto armado colombiano ponen de manifiesto la profundidad y extensión de la violencia en la vida de las mujeres, pero también su enorme valor de afrontamiento y su actitud proactiva frente a los hechos (Ruta Pacífica de las Mujeres, 2013: 405). 


\section{El cuidado de otros y otras: anclaje de vida}

Ese valor, esa actitud proactiva de las mujeres, bebe especialmente del compromiso por el cuidado de sus hijos y los seres más allegados. "En situaciones extremas y de desestructuración social y familiar como en el desplazamiento, se hace evidente la capacidad de las mujeres para responder y para intentar reestructurar la vida, en función especialmente del cuidado a sus hijos y otros familiares cercanos" (Ruta Pacífica de las Mujeres, 2013: 331).

Y es que "en su recorrido de víctimas a sobrevivientes hubo anclajes que les dieron el sentido y la fuerza necesaria para no abandonarse al dolor y seguir adelante recomponiendo lo que la violencia había destruido" (Ruta Pacífica de las Mujeres, 2013: 71). Esos anclajes se van a relacionar con lo que Leonardo Boff (2002: 77) denomina modo-de-ser-cuidado.

Si bien la socialización en los valores y las praxis del cuidar ha sido, y continúa siendo en muchos lugares del mundo -entre ellos América Latina-, una fuente de subordinación de la mujeres al espacio privado que debemos denunciar, implica también el desarrollo de una serie de habilidades que ha permitido a las mujeres pasar en situaciones límites no sólo de víctimas a sobrevivientes sino, en no pocas ocasiones, de sobrevivientes a constructoras de paz.

En los testimonios de las mujeres colombianas podemos distinguir tres ámbitos de acción en los cuales se focaliza el empeño de las mujeres por preservar la vida frente a la violencia de los actores armados (Ruta Pacífica de las Mujeres, 2013: 71), tres ámbitos de acción relacionados con la praxis del cuidar: $a$. Resistir y movilizarse en nombre de los vínculos, $b$. Rehacer las condiciones de humanidad. $c$. Tejer la vida colectiva.

Resistir y movilizarse en nombre de los vínculos

Uno de los anclajes que ayuda a las mujeres a sobreponerse al dolor es la fuerza de los vínculos que las unen con las personas queridas. "Las criaturas a su cargo fueron el motor que las impulsó para sobreponerse a la aflicción, resistir y activarse para darles un futuro" (Ruta Pacífica de las Mujeres, 2013: 72). "Las mujeres sintieron a veces que aun deseando la muerte, el compromiso con la vida y con las personas a su cargo las obligaba a seguir viviendo" (Ruta Pacífica de las Mujeres, 2013: 430).

Es una experiencia dialéctica entre el peso de la responsabilidad abrumadora y la voluntad incontestable de responder por los hijos e hijas, quienes 
son expectativa y esperanza de futuro y "constituyen una esperanza de sentido, de que el propio sufrimiento no haya sido en vano, que haya servido para otros" (Ruta Pacífica de las Mujeres, 2013: 72).

El vínculo con las hijas e hijos es tal vez el argumento más repetido para dar razón de lo que empujó a las mujeres a seguir adelante. El amor, la responsabilidad o la obligación asumida hacia ellos son los motores que sostienen un proceso de superación de la aflicción que a veces parecía imposible lograr. Los hijos son pues el principal motivo, según los testimonios de las mujeres entrevistadas, para salir del lugar del dolor y dejarlo atrás, para sacar fuerzas de donde casi no quedan, para enraizarse en el presente y mirar el futuro (Ruta Pacífica de las Mujeres, 2013: 437).

"Eso también fue más que una carga un motivo para continuar" (Ruta Pacífica de las Mujeres, 2013: 439), relataba una mujer que se quedó al cuidado de sus hermanos pequeños. Apostar por la continuidad de la vida después de haber sido víctima de la violencia, y a pesar incluso de la enfermedad, va estrechamente ligado a la responsabilidad que las mujeres asumen en relación con sus hijas e hijos.

Si las hijas y los hijos son el argumento que da sentido para seguir adelante con la vida, también son el motivo por el cual las mujeres no se permiten flaquear, dejarse llevar por los recuerdos ni desmoronarse. "Aunque todo eso supone también una sobrecarga afectiva y social importante, que puede dejar fuera sus propias necesidades psicológicas y de apoyo" (Ruta Pacífica de las Mujeres, 2013: 439).

Según Luis Rojas Marcos (2010: 63), son seis los pilares de la resiliencia, que sustentan la capacidad humana para afrontar, resistir y superar emocionalmente circunstancias muy adversas: las conexiones afectivas, ciertas funciones ejecutivas personales, la autoestima, el pensamiento positivo, los motivos para vivir y la inclinación a localizar el centro de control dentro de uno mismo.

Un elemento necesario de la resiliencia humana es la conexión afectiva con los demás (Rojas, 2010: 64, 83 y 93):

Las relaciones afectivas constituyen el incentivo más frecuente para sobrevivir, el mejor antídoto contra los efectos nocivos de cualquier desgracia, el principal pilar de la resiliencia humana [...] Mantener los lazos de amor es el motivo más frecuente para existir y evitar la muerte, la razón más poderosa para sobrevivir. La mayoría de las personas menciona a seres queridos a los que no quieren apenar, abandonar o perder como la razón principal para luchar contra la adversidad y no tirar la toalla. 
Rehacer las condiciones de vida necesarias para el desarrollo humano

En estrecha relación con la importancia de los vínculos, pero también como afirmación de la propia dignidad, está el empeño de las mujeres por rehacer una y otra vez las condiciones de vida necesarias para el desarrollo humano. La importancia de recomponer los elementos básicos para una vida digna, para la sostenibilidad de la vida. "Existe una prioridad absoluta de restablecer unas mínimas condiciones para satisfacer las necesidades humanas elementales que hacen que las personas puedan serlo con dignidad" (Ruta Pacífica de las Mujeres, 2013: 74).

A través de los testimonios recogidos se detecta que el valor de la vida es central para las mujeres [...] convirtiéndose muchas veces en el principal sostenimiento económico y afectivo [...] Es esta decisión profunda de preservar la vida la que, seguramente, explica su capacidad, su fortaleza para reconstruir una y otra vez, desde las cenizas, todo lo que ha sido destruido en este conflicto: la casa para habitar, las relaciones y los afectos, las fuentes de subsistencia, etc. (Ruta Pacífica de las Mujeres, 2013: 70).

"Las mujeres han tratado de mantenerse activas de forma que las situaciones de la vida cotidiana u otras experiencias positivas puedan ayudarles a tener la mente ocupada en otras cosas, a distraerse, centrarse en otros aspectos de sus vidas y disminuir el malestar" (Ruta Pacífica de las Mujeres, 2013: 154). Es una forma de actuar, de intervenir, de tomar el control y de mantener activas las funciones ejecutivas, otro pilar de la resiliencia (Rojas, 2010: 125).

En muchas ocasiones esto ha implicado un cambio del rol de las mujeres y su papel al interior de la familia al haberse convertido en la principal fuente de sostenimiento económico y afectivo para la misma. "Porque allá fíjate que esto que yo viví, las que tomábamos las iniciativas éramos las mujeres, eran muy poquitos los hombres que se organizaban, las mujeres éramos las que liderábamos, las que decíamos vamos a hacer lo uno, vamos a hacer lo otro" (Ruta Pacífica de las Mujeres, 2013: 419).

En Frente al limite, Tzvetan Todorov (1993: 84) recoge los testimonios sobre la vida en los campos de concentración nazi y nos relata cómo las actividades de cuidado mutuo entre los presos en los campos nazis eran bastante más abundantes entre las mujeres que entre los hombres.

Se puede partir de esta constante: proporcionalmente, las mujeres han sobrevivido mejor en los campos que los hombres: en términos cuantitativos, pero también en el plano psicológico. Las mujeres se mostraban más prácticas y más susceptibles de ayudarse mutuamente. 
Así, las mujeres construyen un nuevo tipo de liderazgo, "socialmente reconocido, vinculado al concepto del cuidado" (Hernández y Espinar, 2013: 227). Una idea de liderazgo que se va construyendo a partir de su propia experiencia y no es exactamente la misma que la de sus compañeros varones. "Las mujeres realizan un proceso de empoderamiento en el ámbito privado que acaba trasladándose a lo público, en una especie de dinámica de transformación ascendente" (Hernández y Espinar, 2013: 236).

Los contextos de conflicto armado pueden exacerbar las relaciones de género tradicionales pero también suponer una oportunidad para el empoderamiento, la ruptura de roles y la reorganización social. Este es el caso del conflicto colombiano, donde numerosas mujeres, desde posiciones de liderazgo o desde el anonimato, se han convertido en agentes de cambio social, participando activamente en movimientos de resistencia y paz (Hernández y Espinar, 2013: 225).

A través de las actividades del cuidar y del sostenimiento de la vida, las mujeres son capaces de afectar su entorno, ello las dota de autoestima por el reconocimiento de capacidades que supone, y también de seguridad, al sentir que ejercen un cierto grado de control sobre los eventos y que pueden dirigir, aunque sea parcialmente, sus propias vidas.

Reconocer nuestra capacidad de dirigir nuestra vida y adueñarnos del centro de control en momentos difíciles, peligrosos o desconcertantes ayuda a superarlos, pues nos estimula a tomar la iniciativa para tratar activamente de dominar las cosas y protegernos (Rojas, 2010: 80). "Las personas que localizan el centro de control dentro de sí mismas y piensan que dominan razonablemente sus circunstancias resisten mejor y tienen más probabilidades de sobrevivir" (Rojas, 2010: 96).

Está demostrado que los profesionales sanitarios y los especialistas en rescates tienen más posibilidades de afrontar con éxito un desastre porque centran su atención en el trabajo que deben hacer, en la misión de socorrer a los afectados y, como consecuencia, dejan menos espacios abiertos para que les invada el miedo y la confusión. Igualmente, los damnificados que toman la iniciativa y deciden echar un cable a quienes tienen a su alrededor también gozan de más altas probabilidades de superar la coyuntura. Auxiliar y proteger al prójimo los transforma de víctimas en rescatadores (Rojas, 2010: 124-125).

Tejer la vida colectiva

El cuidado se convierte en fuente de superación de la adversidad, de resiliencia, no sólo a través de la fuerza de los vínculos y del compromiso con las actividades cotidianas necesarias para la sostenibilidad de la vida; la partici- 
pación creciente de las mujeres en actividades comunitarias de cuidado, especialmente a otras víctimas del conflicto será un elemento fundamental a tener en cuenta. "Su capacidad de tejer relaciones les ayudó a rehacerse como mujeres, recomponiendo a su vez el entramado afectivo cercano y participando muchas veces en organizaciones y proyectos comunitarios" (Ruta Pacífica de las Mujeres, 2013: 75). La creación o la participación en grupos de mujeres ha sido un modo de hallar apoyo y darlo, de crear espacios para compartir la experiencia y darle sentido.

Las mujeres muestran empatía con otras que puedan estar viviendo situaciones similares a las que ellas han atravesado y sienten que su ayuda es importante, como lo fue para ellas el apoyo recibido en momentos de gran aflicción. "En ese reconocimiento de las otras, las mujeres se están construyendo 'a sí mismas' están fortaleciendo su autonomía y capacidad de liderazgo y están transformando roles que históricamente las situaban en posiciones de sumisión y dependencia" (Ruta Pacífica de las Mujeres, 2013: 418).

En los grupos comunitarios de ayuda, las mujeres "decidieron contar su experiencia porque tiene sentido para ellas poner su verdad al alcance de otras y otros" (Ruta Pacífica de las Mujeres, 2013: 70). "El sentir junto a otras mujeres que han vivido experiencias de despojo similares ayuda a mitigar el dolor de la nostalgia” (Ruta Pacífica de las Mujeres, 2013: 411). Los testimonios de las mujeres colombianas recogidos por la Ruta Pacífica de las Mujeres no pueden ser más directos y transparentes, "yo sé qué sentía esa mamá y ella sabía qué sentía yo" (Ruta Pacífica de las Mujeres, 2013: 412). Pero también la prevención, una expresión de profunda sororidad, el deseo de que otras no vivan lo que ellas vivieron (Ruta Pacífica de las Mujeres, 2013: 411).

La sensibilidad de las otras mujeres con el dolor de las víctimas ha contribuido al afrontamiento positivo del trauma y también ha otorgado sentido a quienes son solidarias, convirtiendo esta circunstancia en un aporte de doble vía al afrontamiento, ${ }^{5}$ que termina fortaleciendo a las mujeres en la reconstrucción de sus vidas y a la organización misma (Ruta Pacífica de las Mujeres, 2013: 423).

Ayudar a otros en trances difíciles nos hace más resistentes al estrés y al agotamiento físico y emocional. Además, nos protege de la tendencia a aislarnos y posiblemente ahogarnos en emociones negativas o pensamientos agoreros. Una vez pasado el desastre, el comportamiento altruista continúa estimulando la autoestima positiva, también pilar de la resiliencia, pues induce en nosotros el sentido de la propia competencia y la

5 Para las que reciben ayuda (acompañamiento legal y psicosocial), pero también para las que la dispensan. 
satisfacción de haber contribuido a la seguridad de otros. Los afectados por cualquier tipo de calamidad que se han sentido útiles durante la crisis y han visto que tuvieron un impacto positivo en el bienestar o en la vida de otros, resisten y se recuperan mejor de las secuelas emocionales (Rojas, 2010: 125).

Así también lo señala Todorov a la luz de la experiencia de los presos en los campos de concentración nazi, el donador es también un beneficiario. Recibe, independientemente de toda recompensa futura, una ganancia por el cumplimiento mismo de su acto.

Pero, ¿por qué era esto así? Se pueden buscar a este hecho muchas explicaciones. Una de ellas consiste en decir que a través del cuidado por el otro se tiene la impresión de reencontrar la dignidad y el respeto hacia uno mismo, puesto que se cumplen actos que la moral ha considerado siempre como loables; es así como el sentimiento de dignidad refuerza nuestra capacidad de mantenernos vivos (Todorov, 1993: 95).

Eso sube la autoestima porque uno se siente importante. Eso llena de satisfacción a uno, de que no todo es que me lo den, que me lo den, yo también puedo dar (Ruta Pacífica de las Mujeres, 2013: 412).

Esas formas de ayuda mutua, donde algunas de las mujeres entrevistadas ayudaron a otras que veían en peor situación que ellas, supone un ejercicio de reciprocidad y de fortalecimiento personal.

Las voces de las mujeres colombianas que dieron testimonio refieren cómo los cambios que tuvieron lugar en sus vidas supusieron para algunas de ellas pasar a ocupar espacios, realizar actividades y asumir papeles que, en la sociedad colombiana, no se asocian al rol que cumplen las mujeres (Ruta Pacífica de las Mujeres, 2013: 444). "De la guerra obtuvieron una 'ganancia', por decirlo así, se constituyeron en sujetos”, señalaba Marina Gallego, coordinadora nacional de la Ruta Pacífica de las Mujeres, en una entrevista reciente. Esto se debe a que una de las tantas maneras que encontraron para sobrellevar lo vivido en el conflicto fue agruparse para respetar sus derechos y reclamarle al Estado que no haya impunidad.

Mujeres que encabezan procesos de lucha por transformar las estructuras que las oprimen; que reclaman su derecho a participar en igualdad de condiciones en los procesos de toma de decisiones; que se reconocen a sí mismas como sujetos políticos, como actores de un cambio que presenta a su vez unas características propias e integra los valores que derivan de sus experiencias vitales como mujeres, los valores del cuidado (Hernández y Espinar, 2013: 243).

El crecimiento postraumático alude a esa valoración personal de renovación y transformación experimentada por muchos supervivientes tras experiencias desafortunadas. "Hay supervivientes a quienes su pugna por vencer 
la adversidad les revela talentos y facetas novedosas, creativas o altruistas de su personalidad que desconocían. Este hallazgo les hace contemplar nuevas opciones o posibilidades en su futuro programa de vida, tanto en lo personal como en lo profesional" (Rojas, 2010:206).

Las mujeres constatan cómo en estas acciones solidarias se descubren y fortalecen liderazgos femeninos que promueven la convivencia pacífica. "Y fíjate que ahí vi que tengo esta vocación que no había descubierto. Ahí empecé a servir en la comunidad, ya yo era una cabeza visible" (Ruta Pacífica de las Mujeres, 2013: 413). En esta construcción de liderazgos femeninos destacan narrativas de mujeres indígenas para quienes ésta ha sido una experiencia de reconocimiento y valoración de los propios saberes y poderes.

Las actividades de cuidado dignifican al que las ejerce dotándole de un sentido de satisfacción y de valía, permitiéndole curarse a sí mismo, aceptando tras el conflicto las experiencias vividas. De hecho, un pensamiento que suele acompañar como parte de una herencia a las personas que han convivido con otras que sufrieron en una situación límite es: ¿hice lo suficiente?, ¿podría haber hecho más? (Oliner, 1995: 94).

"Puede también observarse que el individuo encuentra muchas más fuerzas en sí cuando se ocupa de otro que cuando no tiene más ocupación que él mismo" (Todorov, 1993: 95). El sentimiento de utilidad y de interconexión aumenta la autoestima personal y el sentimiento de felicidad. "La recompensa está contenida en el acto mismo, y al preocuparse del otro uno no deja de preocuparse de sí mismo: aquí, el más dispendioso es el más rico" (Todorov, 1993: 96).

Yo pienso que es lo único que podría sanar un poco mi herida y la de muchas mujeres, porque el poder ayudar a una persona en eso que uno no pudo tener, eso sana, y le da a uno satisfacción y sentido de vivir (Ruta Pacífica de las Mujeres, 2013: 412).

\section{Conclusión}

En este artículo hemos presentado la praxis del cuidar como fuerza autopoiética y de resignificación del ser humano como agente y como fuente de resiliencia ante situaciones adversas. Un análisis fenomenológico del legado de las mujeres como constructoras de paz nos permite reconstruir el cuidado como eje de intersubjetividad y Cultura de Paz, recuperándolo así como valor humano y no meramente de género.

Renunciar al cuidado, destino tradicional de la mujer, ¿es una tarea exaltante? La mujer podrá así, tal vez, parecerse más al hombre, pero los dos serán tanto menos humanos. 
Si hay una tarea exaltante, ¿̇no será más bien la de hacer comprender a los hombres -a todos los hombres y no solamente a algunos- que, sin el cuidado, ellos se arriesgan a no ser más que machos, necesitados todavía de nacer a la verdadera humanidad? Mantenerse humano, ¿es sacrificarse a abstracciones o preocuparse de seres particulares? Nada de esto significa que uno deba hacer el elogio incondicional de lo femenino o de lo maternal. Lo que es admirable como acto -el cuidado- puede cesar de serlo desde que se le congela en una actitud automática (Todorov, 1993: 88).

La filosofía del cuidar puede contribuir a la construcción de una filosofía posandrocéntrica en, al menos, dos sentidos. En primer lugar, por constituir un marco de referencia en el que se disuelven los reduccionismos y dualismos que han dibujado el pensamiento hegemónico occidental y, en segundo lugar, por contribuir a la refundación de un concepto de ser humano relacional e interdependiente.

Superar los dualismos no es tarea sencilla, forman parte de la inercia mental que heredamos y que contribuimos a perpetuar. Además muchos dualismos se construyeron con el hálito de la emancipación y el empoderamiento, tales como el de trascendencia frente a inmanencia, tematizado por Simone de Beauvouir en El Segundo Sexo y al que tanto debe el feminismo.

Sin embargo, éste como otros de los dualismos de la racionalidad occidental es - a pesar de su éxito o quizás por ello - reduccionista y no refleja la complejidad y permeabilidad de las experiencias humanas. Así, por ejemplo Alicia Puleo (2005: 206) reconoce cómo renegar de la inmanencia fue "un canto a la libertad que ha inspirado gran parte de nuestra vida pero que encierra el desprecio de la naturaleza externa e interna". "El trabajo de cuidados debe ser entendido como una capacidad importante que forma parte del proceso de realización de una persona plena y no sólo como una carga histórica que se debería sacudir de los hombros de las mujeres" (Rendueles, 2013: 150-151).

\section{Bibliografía}

Amorós, Celia (2006), "Filosofía y Feminismo en la Era de la Globalización”, en Guerra, María José y Ana Hardisson [eds.], 20 Pensadoras del siglo XX, Oviedo: Nobel.

Arendt, Hannah (2005), La condición humana, Barcelona: Paidós Ibérica.

Benhabib, Seyla (1990), "El otro generalizado y el otro concreto: la controversia KohlbergGilligan y la teoría feminista”, en Benhabib, Seyla y Cornell, Drucilla [eds.], Teoría Feminista y Teoria Crítica, Valencia.

Boff, Leonardo (2002), El cuidado esencial. Ética de lo humano, compasión por la tierra, Madrid: Trotta. 
Boulding, Kenneth E. (1993), Las tres caras del poder, Barcelona: Paidós.

Breines, Ingeborg et al. (2002), Mujeres a favor de la paz. Hacia un programa de acción, Madrid: Narcea.

Cockburn, Cynthia (2009), Mujeres ante la guerra. Desde dónde estamos, Barcelona: Icaria.

Comins Mingol, Irene (2009), Filosofia del Cuidar, una Propuesta Coeducativa para la Paz, Barcelona: Icaria.

Comins Mingol, Irene (2010), “El cuidado, eje vertebral de la intersubjetividad humana”, en Comins Mingol, Irene y Sonia París Albert [eds.], Investigación para la Paz: Estudios Filosóficos, Barcelona: Icaria.

Comins Mingol, Irene (2013), "Philosophical Perspectives on Caring Citizenship", en Peace Review: A Journal of Social Justice, special issue Occupy Movements and the Indignant Figure, vol. 25, núm. 3, San Francisco: University of San Francisco.

Cruz, Manuel (2009), Menú degustación. La ocupación del filósofo, Barcelona: Península.

Díez Jorge, Ma Elena y Margarita Sánchez Romero [eds.] (2010), Género y Paz. Teorías y prácticas de una cultura de paz, Barcelona: Icaria.

Galtung, Johan (2003), Paz por medios pacíficos. Paz y conflicto, desarrollo y civilización, Gernika: Bakeaz-Gernika Gogoratuz.

Gilligan, Carol (1986), La moral y la teoria. Psicología del desarrollo femenino, México: Fondo de Cultura Económica.

Hernández Sánchez, Maribel y Eva Espinar Ruiz (2013), “Género, liderazgo y construcción de paz en Colombia: una aproximación desde el método biográfico", en Comins Mingol, Irene y Francisco A. Muñoz [eds.], Filosofías y praxis de la paz, Barcelona: Icaria.

Kohlberg, Lawrence (1976), “Moral Stages and Moralization”, en Lickona, T. [ed.], Moral Development and Behavior: Theory, Research and Social Issues, Nueva York.

Magallón Portolés, Carmen (2006), Mujeres en pie de paz, Madrid: Siglo XxI.

Martínez Guzmán, Vicent (2004), “Teorías de la guerra en el contexto político de comienzos del siglo Xxı”, en Filosofía Práctica y Persona Humana, núm. 262, Salamanca: Universidad Pontificia de Salamanca.

Martínez Guzmán, Vicent; Comins Mingol, Irene y París Albert, Sonia (2009), "La nueva agenda de la filosofía para el siglo XXI: los estudios para la paz”, en Convergencia, Revista de Ciencias Sociales, número especial de aniversario IA, Toluca, Estado de México: Universidad Autónoma del Estado de México.

Maturana, Humberto y Francisco Varela (2006), De máquinas y seres vivos. Autopoiesis: la organización de lo vivo, Santiago de Chile: Editorial Universitaria.

Muñoz, Francisco A. (2001), La Paz imperfecta, Granada: Universidad de Granada.

Oliner, Pearl M. y Samuel P. Oliner (1995), Toward a Caring Society. Ideas into Action, London: Praeger.

Pastor Yuste, Raquel (2007), “Género y élites políticas: ¿Un estilo de liderazgo femenino?”, en Arenas Fernández, Gloria et al., Pensando la educación desde las mujeres, Málaga: Universidad de Málaga. 
Puleo, Alicia (2005), "Los dualismos opresivos y la educación ambiental”, en Isegoría, núm. 32, Madrid: Instituto de Filosofía Csic.

Raven-Roberts, Angela (2002), “Participación, ciudadanía e implicaciones de las mujeres en una Cultura de Paz”, en Breines, Ingeborg et al. [eds.], Mujeres a favor de la paz. Hacia un programa de acción, Madrid: Narcea Ediciones.

Reardon, Betty (2001), Education for a culture of peace in a gender perspective, París: Unesco. Reardon, Betty (2010), "La problemática del patriarcado: hacia una teoría de género de la violencia global”, en Díez Jorge, Ma Elena y Margarita Sánchez Romero [eds.], Género y paz, Barcelona: Icaria.

Rendueles, César (2013), Sociofobia. El cambio politico en la era de la utopía digital, Madrid: Capitán Swing.

Reverter Bañón, Sonia (2010), "La deriva teórica del feminismo", en Daimon. Revista Internacional de Filosofia, Suplemento 3, Murcia: Universidad de Murcia.

Rojas Marcos, Luis (2010), Superar la adversidad. El poder de la resiliencia, Madrid: Espasa. Ruddick, Sara (1989), Maternal Thinking: toward a politics of Peace, New York: Women's Press.

Ruta Pacífica de las Mujeres (2013), La Verdad de las Mujeres. Victimas del conflicto armado en Colombia, Bogotá: G2 Editores.

Sevenhuijsen, Selma (2003), "The place of care. The relevance of the feminist ethic of care for social policy”, en Feminist Theory, vol. 4, núm. 2, Thousand Oaks: Sage.

Todorov, Tzvetan (1993), Frente al Limite, Madrid: Siglo XxI.

Irene Comins Mingol. Doctora por la Universitat Jaume I de Castellón, España. Profesora de Filosofía en el Departamento de Filosofía y Sociología de la Universitat Jaume I y codirectora del Máster Universitario en Estudios Internacionales de Paz, Conflictos y Desarrollo de la misma universidad. Líneas de investigación: filosofía para la paz, antropología filosófica, estudios de género y filosofía de la ciencia. Publicaciones recientes: Comins Mingol, Irene y Francisco A. Muñoz [eds.], Filosofías y Praxis de la Paz, Barcelona: Icaria (2013); Comins Mingol, Irene: "Philosophical Perspectives on Caring Citizenship”, en Peace Review: A Journal of Social Justice, vol. 25, núm. 3 (2013); Comins Mingol, Irene, "Carol Gilligan In a Different Voice: Una Revolución en la Teoría del Desarrollo Moral, Un Desafío de la Investigación para la Paz", en Carrillo Flores, Isabel [ed.], Mujeres, Género y Desarrollo: Saberes Interdisciplinares, Servicio de Publicaciones de la Universidad de Vic (2012).

Recepción: 20 de marzo de 2014.

Aprobación: 28 de agosto de 2014. 